\title{
PEUCEDANUM OFFICINALE L. SUBSP. BRACHYRADIUM GARCÍA-MARTÍN Y SILVESTRE: NUEVO TAXON DE UMBELLIFERAE
}

\author{
Felipe GARCÍA MARTÍN y Santiago SILVESTRE
}

RESUMEN. Se propone un nuevo taxon de la familia Umbelliferae, Peucedanum officinale L. subsp. brachyradium García-Martín \& Silvestre, recolectado en Sierra Bermeja (Málaga), dándose su descripción, ilustración y ecología.

Palabras clave. Umbelliferae, Peucedanum, Málaga.

ABSTRACT. Peucedanum officinale L. subsp. brachyradium García-Martín \& Silvestre, a new taxon of Umbelliferae from Sierra Bermeja (Málaga, Spain) is proposed. Description, illustration and ecology are given.

Key words. Umbelliferae, Peucedanum, Málaga.

Gran parte de las especies perennes de las umbelíferas, presentan una fenología caracterizada por su floración y fructificación estivales u otoñales, épocas poco atractivas para las recolecciones botánicas. Si a esto se añade el pequeño número de indivíduos en muchas poblaciones y la necesidad de frutos maduros para llegar a una determinación correcta, no es de extrañar que indivíduos cercanos a los $2,5 \mathrm{~m}$, y en áreas bien conocidas botánicamente, hayan pasado desapercibidos.

Peucedanum officinale L. subsp. brachyradium García-Martín y Silvestre

Planta perennis. Caule erecto, $60-250 \mathrm{~cm}$, glabro, solido, basi foliorum cincto; foliis inferioribus amplis, 4-6 ternatisectis, laciniis linearibus; fol. caulinis ninoribus minusque divisis,(2-)3 ternatisectis, summis ad vaginas reductis. Inflorescentia paniculata. Umbella centrali 12-18 radiata, radiis inaequilongis, ;involucri (0-) 1-2(-5) phyllis setaceis; umbellulis 9-16 floridis; involucelli 5-8 phyllis. Petalis luteis. Fructu 7,6-9,7 x 4,5-6 mm, elliptico vel obovato, pedicello duplo majore; calycis laciniis brevissimis; stylis 1-1,2 mm, stylopodio conico subaequilongis; vittae valleculares solitariae, commisurales 2 ad totum fructum.

Plantas perennes, de hasta $250 \mathrm{~cm}$. Tallo muy ramificado desde su parte basal. Hojas basales pecioladas, 4-6 ternatisectas, con lóbulos terminales de 20-55 x 0,8-1,3 mm, lineares, canaliculados; hojas caulinares sentadas, (2-)3 ternatisectas, las más superiores reducidas a la vaina. Umbela principal con 12-18 radios de 15-40 mm, muy desiguales y (0-)1-2(-5) brácteas lineares; 9-16 radios secundarios y 5-8 bracteolas. Pétalos amarillos. Frutos de 7,6-9,7 x 4,5$6 \mathrm{~mm}$, hasta dos veces más largos que los pedicelos, elípticos u obovados; dientes del cáliz 


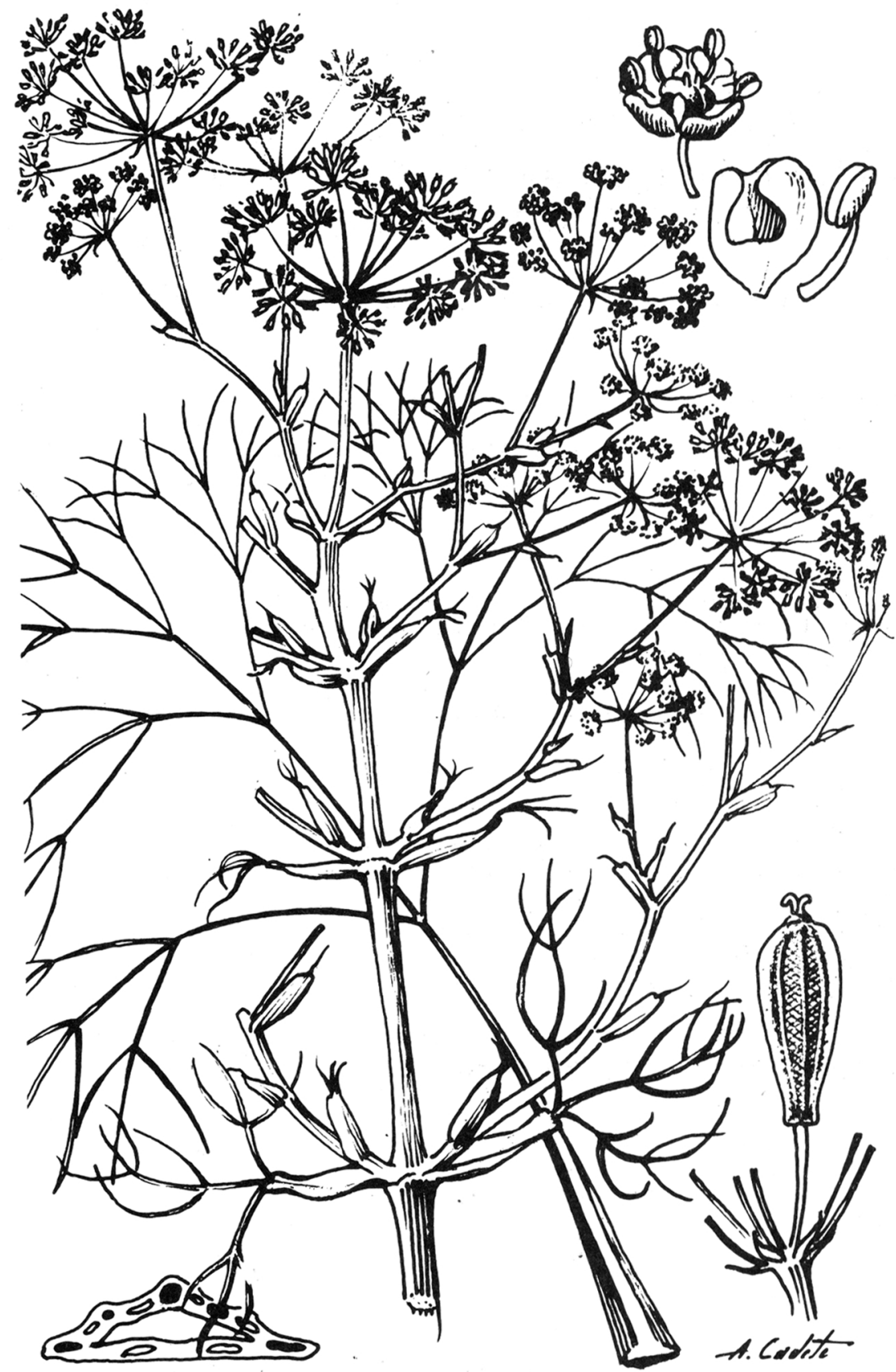

Fig. 1. Peucedanum officinale L. subsp. brachyrradium García Martín y Silvestre. 
inconspícuos; estilos de 1-1,2 mm, caducos; estilopodio cónico, tan largo o casi como los estilos; 1 vita por valécula y dos comisurales completas. Fl. IX-X, fr. XI.

Typus. Málaga: Estepona, Sierra Bermeja, peridotitas, 800-900 m s.m., XI. 1989, F. García-Martín \& S. Silvestre (Holotypus, SEV 133256; Paratypus, Málaga, Estepona, Sierra Bermeja, peridotitas, 800-900 m s.m., 3.X.1989, F. García-Martín \& S. Silvestre, MA y MGC).

Distribución y ecología. Parece tratarse de un edafoendemismo asociado a las peridotitas de la Sierra Bermeja (Estepona, Málaga), posiblemente en inmediato peligro de extinción, ya que tras repetidas búsquedas sólo hemos detectado una población con dos indivíduos en suelos con fuerte pendiente, formando parte de un matorral de Halimio atriplicifolii-Digitaletum laciniatae Rivas Goday \& Rivas Martínez, 1967 (Staehelino-Ulicion baetici Rivas Goday \& Rivas Martínez, 1967), que se desarrolla bajo una cubierta de Pinus pinaster (Pino pinastri-Quercetum cocciferae Cabezudo, Nieto Caldera \& Pérez Latorre, 1989).

Cariología. Se ha estudiado cariológicamente material (botones florales) recolectado en el mes de mayo de 1991, no habiendo sido posible precisar con exactitud su número cromosómico, si bien en las mitosis del conectivo hemos contado c. 60 cromosomas, lo que nos hace suponer que pueda tratarse de un taxon hexaploide. Este carácter lo presenta únicamente el complejo de $P$. officinale L. (Silvestre, 1977; Frey, 1989). La confirmación de $2 n=66$ para este taxon nos llevaría a concluir su condición de esquizoendémico, cuyos vicariantes serían las restantes subespecies de $P$. officinale L. (s. Frey, 1989).

Afinidades. $P$. officinale L. subsp. brachyradium presenta unos caracteres vegetativos muy similares a los de las subespecies officinale y stenocarpum (Boiss. \& Reuter) Font Quer, de las que difiere claramente por su inflorescencia y dimensiones relativas de frutos y pedicelos. Mayor es su afinidad con la subespecie longifolium (Waldst. \& Kit.) R. Frey, del que se diferencia por sus radios, en menor número y de menor longitud, por su umbela principal con menor número de flores y por las dimensiones del fruto (de 5,5-7 x 4-4,5 en la subespecie longifolium frente a 7,6-9,7 x 4,5-6 mm en la subespecie brachyradium), independientemente del aislamiento geográfico y las diferentes condiciones ecológicas.

\section{BIBLIOGRAFÍA}

FREY, R. - 1989- Taxonomische Revision der Gattung Peucedanum: Sektion Peucedanum und Sektion Palimbioidea (Umbelliferae). Candollea, 44: 257-327.

SILVESTRE, S. - 1977- Contribución al estudio cariológico de la familia Umbelliferae en la Península Ibérica. II. Lagascalia, 7(2): 163-172.

(Aceptado para su publicación en Junio de 1992)

Dirección de los autores: Departamento de Biología Vegetal y Ecología, Universidad de Sevilla. 